\title{
Estimating Glenoid Fossa width for Instability-related Bone loss with CT Scan in a Chilean Sample
}

\author{
Estimación del Ancho de la Fosa Glenoidea para la Pérdida Ósea Relacionada \\ con Inestabilidad con Tomografía Computarizada en una Muestra Chilena
}

\author{
Julio Contreras ${ }^{1,2,3,4}$; Claus Ogrodnik ${ }^{2}$ \& Pablo Khek ${ }^{2}$
}

CONTRERAS, J.; OGRODNIK, C. \& KHEK, P. Estimating glenoid fossa width for instability-related bone loss with CT scan in a Chilean sample. Int. J. Morphol., 39(5):1487-1492, 2021.

SUMMARY: Glenoid fossa bone loss has been associated with recurrence and failure after glenoid labrum repair for shoulder instability. Quantification of glenoid fossa bone loss is critical for the successful treatment of glenohumeral instability. The aim of this paper was to estimate a linear regression model based on glenoid height in CT scan adjusted for age and sex to calculate glenoid fossa width in a healthy Chilean sample. CT scans of 101 shoulders were reviewed. The mean age was 51.96 years (SD 19.16; range, 15-88 years) with 53 females and 48 male patients. Studies with signs of bone loss, instability, fracture, or arthritis were excluded. After 3D-CT reconstruction, the height and width of each glenoid fossa was measured using the Owens methodology. All landmarks for the 2 measurements were placed on the most lateral surface of the glenoid fossa margin. Measurements for all shoulders were recorded by 3 observers and repeated on a subset $(n=20)$ of shoulders, under blinded conditions, by the same observer, at least 2 weeks after the initial measurements. Descriptive statistics, intraclass correlation and regression coefficients were calculated with Stata BE $17 \AA$ software. A pvalue of 0.05 was considered significant. A linear regression model was estimated resulting in the formula "Width $=10.97+0.02 *$ Age $+0.41 *$ Height $-1.95 *$ Sex $(1=$ Female, $0=$ Male $)$ ". This model presented all coefficients with $p<0.05$ and an adjusted R2 of 0.73 . Furthermore, it fulfilled the assumption of linearity, normal distribution of errors, independence of errors, and homoscedasticity. Regarding the intraobserver correlation, ICC was 0.76 for height and 0.91 for width; the interobserver ICC was 0.93 for height and 0.86 for width. A 3D-CT specific formula was developed to predict glenoid fossa width based on height with sufficient accuracy to be clinically valuable.

KEY WORDS: Shoulder joint; Glenoid fossa; Anatomy; Shoulder dislocation.

\section{INTRODUCTION}

Glenoid, humeral, or bipolar bone defects are risk factors for recurrence associated with glenohumeral instability (Park et al., 2020; Apostolakos et al., 2021). Since 2000, Burkhart \& de Beer (2000) have identified "glenoid bone deficit" as independent risk factors for glenoid labrum repair failure describing the "inverted pear-glenoid". However, the diagnosis of bone defects was made intraoperatively, and their condition as a "engaging" lesion was evaluated. In 2002, Burkhart et al. (2002) described a method to quantify glenoid bone loss arthroscopically.

Preoperative imaging studies are key for decisionmaking and planning (De Filippo et al., 2020; Stefaniak et al., 2020). There are several modalities, but CT scans are the most suitable to evaluate the glenoid bone defect (Zhang et al., 2020). However, there are many methods described to estimate the size of the glenoid bone defect (Provencher et al., 2010). The most commonly used are the surface area method, the superimposed circle method, the PICO method, and the bare area method (Willemot et al., 2018).

Giles et al. (2015) described the use of glenoid height to estimate its width and thus evaluate the glenoid bone defect. The bone defect is generally anterior affecting the width of the glenoid but does not affect its height. The height of the glenoid and its relationship with the glenoid fossa width is relatively constant at the population level. However, the effect of age, sex, and specific population characteristics can affect its reproducibility. The purpose of this study was to estimate a linear regression model based on glenoid height

\footnotetext{
${ }^{1}$ Shoulder and Elbow Unit. Instituto Traumatológico, Santiago, Chile.

${ }^{2}$ Department of Orthopedics and Trauma. Universidad de Chile, Santiago, Chile.

${ }^{3}$ Shoulder and Elbow Unit. Pontificia Universidad Católica de Chile, Santiago, Chile.

${ }^{4}$ Department of Orthopedics and Trauma. Pontificia Universidad Católica de Chile, Santiago, Chile.
} 
in CT scan adjusted for age and sex to calculate glenoid fossa width in a healthy Chilean sample. Thus, we reviewed 101 CT scans from our institutional database to analyze glenoid anatomy.

\section{MATERIAL AND METHOD}

Sample. CT scans of 214 shoulders from our institutional database were reviewed to analyze the anatomy of the glenoid excluding studies with incomplete images, poor quality, artifacts, or signs of structural, traumatic, or degenerative changes (bone loss, instability, fracture, arthritis, or any alteration of the glenoid anatomy); $101 \mathrm{CT}$ scans were finally processed. The mean age was 51.96 years (SD 19.16; range, 15-88 years) with 53 females and 48 male patients.

CT data acquisition and processing. Patients were scanned in a Siemens SOMATOM® Volume Zoom (Siemens Medical Solutions USA, Malvern, PA). The patients were placed in a supine anatomic position (Gantry tilt $0^{\circ}$ ), and images were obtained in $1-\mathrm{mm}$ increments (Slice collimation $4 ¥ 1 \mathrm{~mm}$ ) along the axial axis of the human body. The images were acquired at $140 \mathrm{kVp}$ and $150 \mathrm{~mA}$ with a $250-\mathrm{mm}$ field of view (FOV), 512 matrix resolution, and rotation speed of 0.75 s per revolution. The FOV of each scan included the entire scapula. Images were processed with RadiAnt DICOM Viewer® 2020.1.1.

Morphometric measurements. Two morphometric measurements were obtained for each of the scapulae: height and width. The height and width were measured based on the methodology published by Owens et al. (2013); the glenoid height was measured as the maximum length from the upper pole of the glenoid (12 o'clock position) to the lower pole (6 o'clock position), and the glenoid fossa width was measured as the maximum diameter in an orthogonal orientation to the previously measured height (Fig. 1). All landmarks for both measurements were placed on the most lateral surface of the glenoid fossa margin. To perform the measurements, a three-dimensional reconstruction (3D-CT) with RadiAnt DICOM Viewer® 2020.1.1 was performed after subtraction of the humeral head. Reconstruction is positioned obtaining a true "en face" view when the image displays the glenoid articular surface with its largest surface extension in the horizontal and vertical planes (Zhang et al.).

Analysis of CT images. All images were measured by a shoulder and elbow surgeon ( 5 years of practice and 10 years of experience) and two orthopedics residents. Forty CT scans were re-evaluated in a blinded mode with at least two weeks of separation for evaluation of the reproducibility of the measurements.

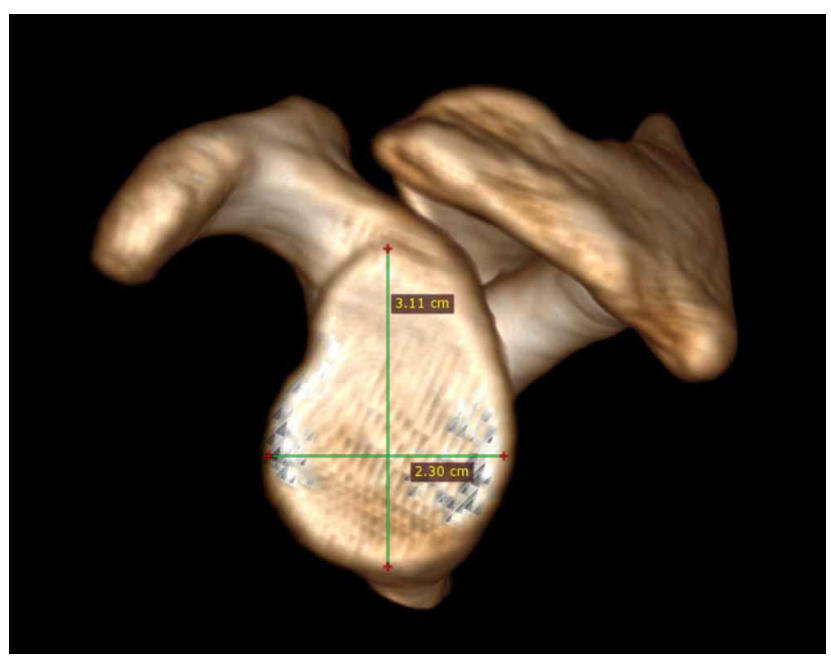

Fig. 1. Morphometric measurements. Two morphometric measurements were obtained: height and width. Glenoid height was measured as the maximum length from the upper pole of the glenoid ( 12 o'clock position) to the lower pole (6 o'clock position) and glenoid fossa width was measured as the maximum diameter in an orthogonal orientation to the previously measured height.

Statistical analysis. Data are presented as mean \pm SD, and the coefficient of variation (CV) was calculated. The Kolmogorov-Smirnov test and Shapiro-Wilk were used to evaluate the normal distribution. A linear regression model was estimated considering the glenoid fossa width as the quantitative dependent variable and the glenoid height as the quantitative independent variable adjusted for age (quantitative) and sex (qualitative, binary). The adjusted R2 and the statistical significance of the regression coefficients were calculated with Student's t-test using Stata BE 17® software. A p-value of 0.05 was considered significant. In addition, the assumption of normal distribution of errors (Kolmogorov-Smirnov test), independence of errors (Durbin Watson test), and homoscedasticity were evaluated for model validation. The intraobserver and interobserver correlation were evaluated with the intraclass correlation coefficient (ICC). The study was reviewed and approved by the ethical committee at our institution.

\section{RESULTS}

The glenoid fossa width was $25.53 \pm 2.41$, and the glenoid height was $35.17 \pm 3.25$ in this sample (Table I). Analysis of the measured height and width values demonstrated a strong correlation of 0.8124 for the full cohort. 
Table I. Variable values.

\begin{tabular}{lcccccc}
\hline Variable & Obs. & Mean & Std. Dev. & VC & Min & Max \\
\hline Height & 101 & 35.17129 & 3.248456 & 9,24 & 27.8 & 42.6 \\
Width & 101 & 25.52772 & 2.41239 & 9,45 & 20.1 & 32 \\
Age & 101 & 51.9604 & 19.16138 & 37,75 & 15 & 88 \\
\hline
\end{tabular}

Obs = Observations; Std. Dev. $=$ Standard deviation; $\mathrm{VC}=$ Variability Coefficient Min = Minimum $;$ Max = Maximum.

A linear regression model was estimated (Fig. 2) resulting in the formula "Width $=10.97+0.02 *$ Age +0.41 * Height $-1.95 *$ Sex $(1=$ Female, $0=$ Male)" (Fig. 3). This model presented all coefficients with $\mathrm{p}<0.05$ and an adjusted
R2 of 0.73 . Furthermore, it fulfilled the assumption of linearity (Fig. 4), normal distribution of errors [KolmogorovSmirnov p > 0.05] (Fig. 5), independence of errors [DurbinWatson d-statistic $=1.84$ ] (Fig. 6), and homoscedasticity (Fig. 7). Regarding the predicted glenoid fossa widths, the regression formula from this CT data set produced a root mean squared error across all shoulders of $1.25 \mathrm{~mm}$. The absolute error margin was $1.01 \pm 0.71 \mathrm{~mm}$ (range: 0.038 to $3.608 \mathrm{~mm}$ ) for the final formula.

Regarding the intraobserver correlation, ICC was 0.76 for height and 0.91 for width; the interobserver ICC was 0.93 for height and 0.86 for width.

\begin{tabular}{|c|c|c|c|c|c|c|}
\hline Source & SS & $d f$ & MS & Number of obs & $=$ & 101 \\
\hline Model & 429.337718 & 3 & 143.112573 & Prob > F & $=$ & 0.0000 \\
\hline Residual & 152.624689 & 97 & 1.5734504 & R-squared & $=$ & 0.7377 \\
\hline Total & 581.962407 & 100 & 5.81962407 & $\begin{array}{l}\text { Adj R-squared } \\
\text { Root MSE }\end{array}$ & $\begin{array}{l}= \\
=\end{array}$ & $\begin{array}{l}0.7296 \\
1.2544\end{array}$ \\
\hline
\end{tabular}

\begin{tabular}{r|rrrrrr}
\hline Width & Coef. & Std. Err. & $\mathrm{t}$ & $\mathrm{P}>|\mathrm{t}|$ & {$[95 \%$ Conf. } & Interval] \\
\hline Height & .4130915 & .0533574 & 7.74 & 0.000 & .3071918 & .5189911 \\
Age & .0201914 & .0071426 & 2.83 & 0.006 & .0060153 & .0343675 \\
Sex & -1.946338 & .3675477 & -5.30 & 0.000 & -2.675819 & -1.216857 \\
_cons & 10.97096 & 1.970683 & $\mathbf{5 . 5 7}$ & 0.000 & 7.059696 & 14.88222
\end{tabular}

Fig. 2. Linear regression model. SS $=$ Sum of squares; $\mathrm{df}=$ Degrees of freedom; MS = Mean squared; obs $=$ observations $; \mathrm{F}=\mathrm{F}$ statistic $;$ Prob $>\mathrm{F}=$ p-value for F statistic; Adj = Adjusted; MSE = Mean Squared Error;_cons = Intercept; Coef. = b coefficient; Std. Err. = Standard Error; $\mathrm{t}=\mathrm{t}$-student statistic; $\mathrm{P}>|\mathrm{t}|=$ p-value for t statistic; Conf. Interval $=$ Confidence interval; _cons = constant.

Glenoid width $(\mathbf{m m})=11+0,02 \times$ Age (years) $+0,41 \times$ Glenoid Height $(\mathrm{mm})-1,95 \times$ sex $(1=$ Female, $0=$ Male $)$

Fig. 3. Adjusted formula. Formula to calculate glenoid fossa width in relation to glenoid height, age, and sex.

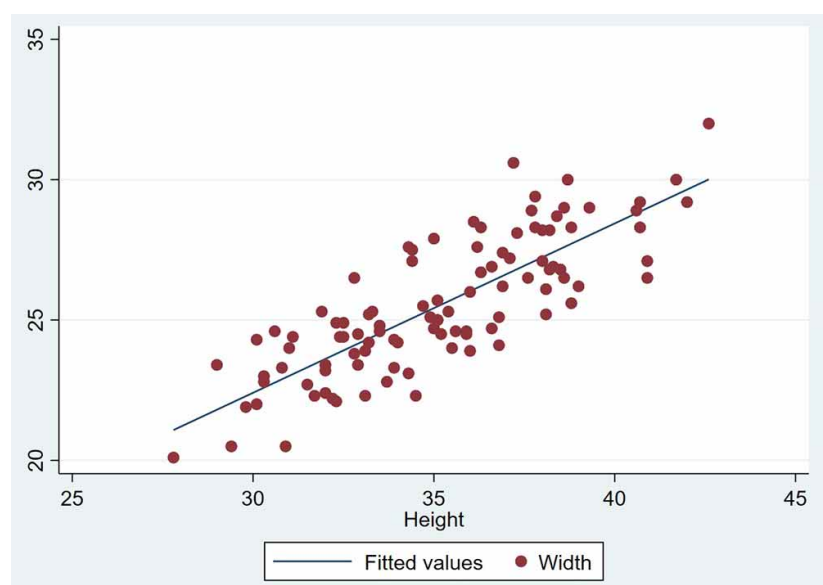

Fig. 4. Linearity assumption. The relationship between glenoid height and width is linear.

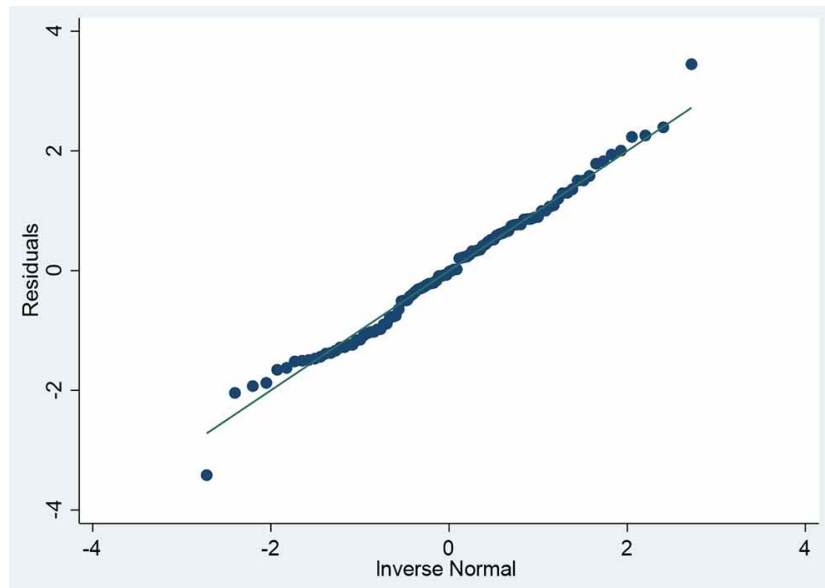

Fig. 5. Normality of errors assumption. The residuals normally distributed in this model. Kolmogorov-Smirnov's test was $\mathrm{p}>0,05$. 


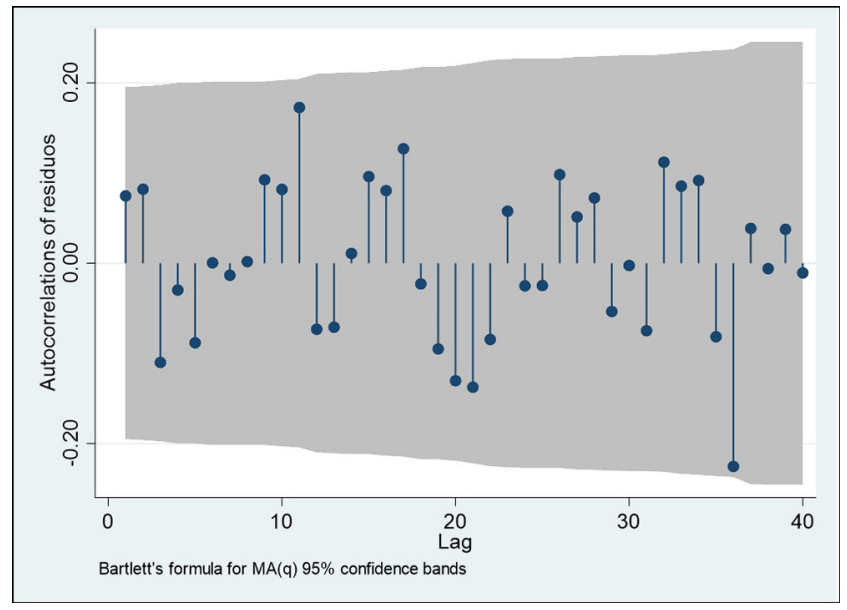

Fig. 6. Independence of errors assumption. The qualitative assessment (graph) rules out correlation between the residuals. The quantitative evaluation with Durbin-Watson d-statistic (1.839626) confirms the independence of errors by discarding the correlation of the residuals by presenting a value close to 2 .
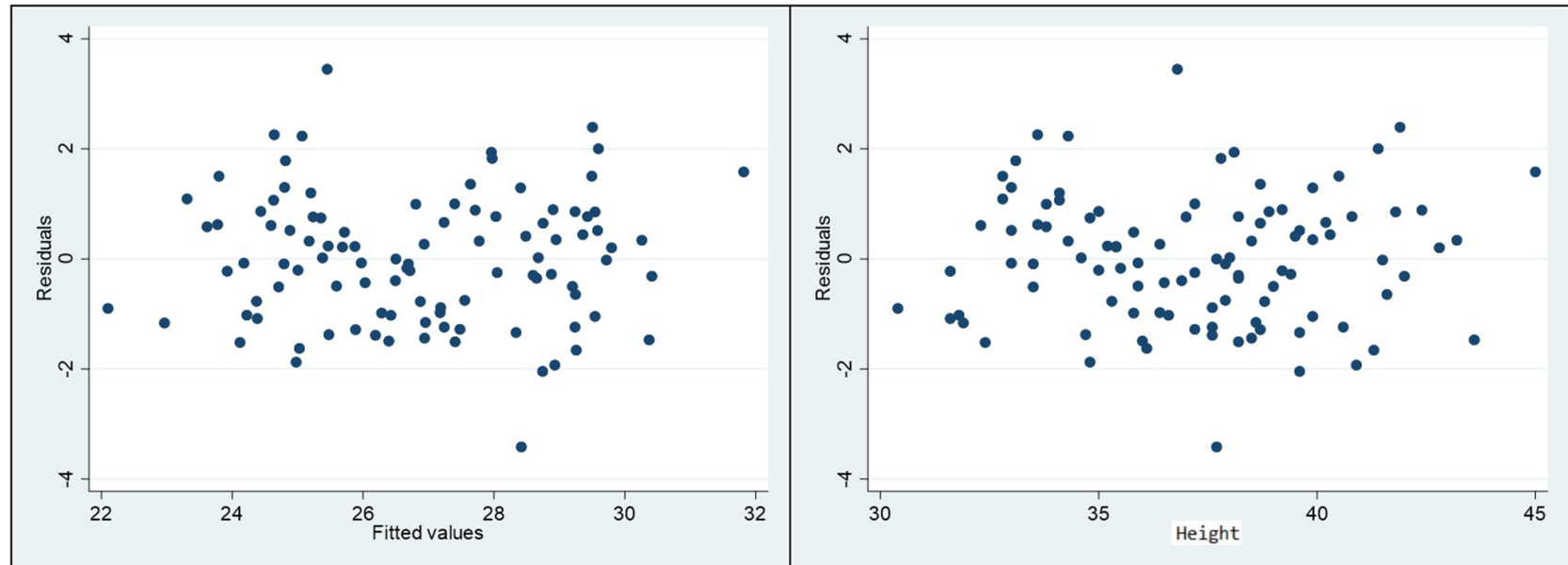

Fig. 7. Equal variances assumption (Homoscedasticity). The variance of the residuals is the same for all values of $x$.

\section{DISCUSSION}

The main finding of our study was a linear regression model that allows one to calculate the glenoid fossa width using the glenoid height adjusted for age and sex. The model is statistically significant, and it explains over $73 \%$ of the correlation with the variables included and is based on reproducible and reliable measurements.

In 2015, Giles et al. declared that “....an inherent problem with the measurement of bone loss is that no true gold standard exists for comparison, as we are estimating the dimensions of a structure that is no longer present...". Even the use of the contralateral morphology does not allow one to establish a standard method of measurement. Several measurement methods are currently in use but there is no agreement on the ideal technique (Sugaya, 2014).
The data from our study confirmed the results of Giles and Owens whereby glenoid height and width are strongly correlated. In addition, we adjusted for age and sex to eliminate bias. Glenoid height is simply and reproducibly measured and is not compromised by glenohumeral instability (bone loss) allowing its use to estimate glenoid fossa width.

Regarding the study modality, the use of 2D images and the use of 3D reconstructions can affect the anatomical measurements at the glenoid level. In our anatomical review of the glenoid morphology in a CT scan (Contreras et al., 2020) using $2 \mathrm{D}$ images, we found that the glenoid size showed an average width of $26 \pm 2.7 \mathrm{~mm}$, a height of $40.3 \pm 3.5 \mathrm{~mm}$, and a vault depth of $26.5 \pm 3.7 \mathrm{~mm}$. Regarding the glenoid fossa width, the $2 \mathrm{D}$ measurement $(26 \pm 2.7 \mathrm{~mm})$ and the $3 \mathrm{D}$ 
measurement $(25.53 \pm 2.41)$ are similar, but the 2D (40.3 \pm $3.5 \mathrm{~mm})$ and $3 \mathrm{D}(35.17 \pm 3.25)$ glenoid height measurement are different. This is probably associated with the measurement method because, according to Owens et al., the glenoid height is the maximum length from the upper pole of the glenoid (12 o'clock position) to the lower pole (6 o'clock position). In the $2 \mathrm{D}$ modality, the measurement is closer to the superior cortex of the supraglenoid tubercle, and thus it may be larger. This model must be used in 3D reconstructions because the use of another modality could lead to overestimations of the glenoid fossa width and therefore an overestimation of the glenoid deficit. This could affect the surgical decision. Giles et al. found similar results for glenoid height and width on CT $(33.3 \pm 2.9 \mathrm{~mm}$ and $26.2 \pm 2.5 \mathrm{~mm}$, respectively). Kubicka et al. (2016) compared 2D and 3D-CT in the assessment of glenoid bone loss and showed that 3DCT reliability was nearly perfect in all measurements even if performed by an inexperienced observer.

In relation to the use of $3 \mathrm{D}$ reconstructions, it is important to consider that the true "en face" view is defined when the image displays the glenoid articular surface with its largest surface extension in the horizontal and vertical planes (Zhang et al.). Nevertheless, this definition is arbitrary and can lead to variability. Here, each evaluator subtracted the humeral head and the three-dimensional positioning of the glenoid in both measurements to obtain excellent intra and interobserver correlation; thus, the effect is probably minimal. Zhang et al. performed a quantitative description of a true "en face" view using the best-sphere fit method. However, we believe that this may complicate estimating the glenoid fossa width. Giles et al. found that intra-observer reliability was good to excellent with an ICC of 0.765 for glenoid fossa width and 0.992 for height $(0.76$ for height and 0.91 for width in our sample). Interobserver reliability also showed high levels of correlation with an ICC of 0.895 and 0.969 for width and height, respectively ( 0.93 for height and 0.86 for width in our sample).

Giles et al. found variations in glenoid size based on sex. Sex-specific regression analyses established that male and female formulas differ from the overall formula above but exhibit only an offset relative to each other similar to our sample with men presenting a $1.95 \mathrm{~mm}$ greater offset.

In relation to precision, we compared the prediction of the formula to the true glenoid fossa width values: a root mean squared error across all shoulders of $1.25 \mathrm{~mm}$ was calculated similar to the $1.2 \mathrm{~mm}$ obtained by Giles et al. The absolute error margin was 1.01. This low level of error indicates that the formulas used for the glenoid height predicted the glenoid fossa width exactly. This allows one to make decisions on the type of treatment with the greatest reproducibility.
In relation to other methods for estimation of glenoid fossa width, the reliability of the bare spot as a central reference point of the glenoid has been questioned. Saintmard et al. (2009) identified the bare spot in less than $48 \%$ of cases during arthroscopy and in only $26 \%$ with CT arthrography. Two cadaveric studies assessed bare spot measurements and showed that this is an unreliable landmark in glenoid measurements (Aigner et al., 2004; Huysmans et al., 2006). Surface measurement of the glenoid is probably the most popular method in clinical use and planning (Stefaniak et al.). The idea of a best-fit circle was developed by Sugaya et al. (2005) on 3D-CT. Baudi et al. (2005) developed the Pico method, which is based on calculating the size of the defect in the affected shoulder as a percentage of the best-fit circle area of the contralateral glenoid. However, the problem with all of these measurements is the lack of a gold standard for comparison.

Limitations of this study include that our sample had patients with a wide age range (15 to 88 years) including some that are beyond the average age group that presents anterior shoulder instability. However, all CT scans were analyzed for signs of degenerative changes ( $52.8 \%$ of studies excluded); thus, the evaluated glenoid measurements should represent the normal anatomy. The formula was also adjusted for age.

CT ensures high resolution and is a gold standard in the assessment of chronic anterior shoulder instability allowing detection and quantification of the lesions (Lansdown et al., 2019), but one major disadvantage of a CT scan is the radiation dose. MRI is one solution: It has no ionizing radiation and is the most useful modality for soft tissue evaluation. However, it is much more expensive, less available, has longer scan times, and depends on technical quality.

The advantages of this study are the inclusion of a sample with many healthy subjects; the use of the gold standard imaging approach (3D-CT); measurement by expert and trained professionals; simple and reproducible measurements; robust statistical evaluation; and an easy-to-use formula applicable to clinical practice.

\section{CONCLUSION}

In conclusion, we found that glenoid height and width are strongly correlated. A 3D-CT specific formula was developed to predict glenoid fossa width based on height with sufficient accuracy to be clinically valuable. As such, the adjusted formula for 3D-CT in a Chilean sample is now described to assist surgeons in quantifying glenoid bone loss. 
CONTRERAS, J.; OGRODNIK, C. \& KHEK, P. Estimación del ancho de la fosa glenoidea para la pérdida ósea relacionada con inestabilidad con tomografía computarizada en una muestra chilena. Int. J. Morphol., 39(5):1487-1492, 2021.

RESUMEN: La pérdida de hueso de la fosa glenoidea se ha asociado con recurrencia y falla después de la reparación del labrum glenoideo por inestabilidad del hombro. La cuantificación de la pérdida ósea glenoidea es fundamental para el tratamiento exitoso de la inestabilidad glenohumeral. El objetivo de este trabajo fue estimar un modelo de regresión lineal basado en la altura glenoidea en una tomografía computarizada ajustada por edad y sexo para calcular el ancho de la fosa glenoidea en una muestra chilena sana. Se revisaron las tomografías computarizadas de 101 hombros. La edad media fue de 51,96 años (DE 19,16; rango, 1588 años) con 53 mujeres y 48 hombres. Se excluyeron los estudios con signos de pérdida ósea, inestabilidad, fractura o artritis. Después de la reconstrucción 3D-CT, se midió la altura y el ancho de cada fosa glenoidea utilizando la metodología de Owens. Todos los puntos de referencia para las 2 mediciones se colocaron en la superficie más lateral del margen glenoideo. Las mediciones de todos los hombros fueron registradas por 3 observadores y repetidas en un subconjunto $(\mathrm{n}=20)$ de hombros, en condiciones ciegas, por el mismo observador, al menos 2 semanas después de las mediciones iniciales. La estadística descriptiva, la correlación intraclase y los coeficientes de regresión se calcularon con el software Stata BE $17 ®$. Se consideró significativo un valor de p de 0,05 . Se estimó un modelo de regresión lineal que resultó en la fórmula "Ancho = 10,97 $+0,02 *$ Edad $+0,41 *$ Altura $-1,95 *$ Sexo $(1=$ Mujer, $0=$ Hombre)". Este modelo presentó todos los coeficientes con $\mathrm{p}<0.05$ y un R2 ajustado de 0.73. Además, cumplió con los supuestos de linealidad, distribución normal de errores, independencia de errores y homocedasticidad. En cuanto a la correlación intraobservador, el CCI fue de 0,76 para la altura y 0,91 para la anchura; el ICC interobservador fue de 0,93 para la altura y 0,86 para la anchura. Se desarrolló una fórmula específica de 3D-CT para predecir el ancho glenoideo en función de la altura con suficiente precisión para ser clínicamente valiosa.

PALABRAS CLAVE: Articulación del glenohumeral; Fosa glenoidea; Anatomía; Luxación de hombro.

\section{REFERENCES}

Aigner, F.; Longato, S.; Fritsch, H. \& Kralinger, F. Anatomical considerations regarding the "bare spot" of the glenoid cavity. Surg. Radiol. Anat., 26(4):308-11, 2004.

Apostolakos, J. M.; Wright-Chisem, J.; Gulotta, L. V.; Taylor, S. A. \& Dines, J. S. Anterior glenohumeral instability: Current review with technical pearls and pitfalls of arthroscopic soft-tissue stabilization. World $J$. Orthop., 12(1):1-13, 2021.

Baudi, P.; Righi, P.; Bolognesi, D.; Rivetta, S.; Rossi Urtoler, E.; Guicciardi, N. \& Carrara, M. How to identify and calculate glenoid bone deficit. Chir. Organi Mov., 90(2):145-52, 2005.

Burkhart, S. S. \& De Beer, J. F. Traumatic glenohumeral bone defects and their relationship to failure of arthroscopic Bankart repairs: significance of the inverted-pear glenoid and the humeral engaging Hill-Sachs lesion. Arthroscopy, 16(7):677-94, 2000.
Burkhart, S. S.; De Beer, J. F.; Tehrany, A. M. \& Parten, P. M. Quantifying glenoid bone loss arthroscopically in shoulder instability. Arthroscopy, 18(5):488-91, 2002

De Filippo, M.; Schirò, S.; Sarohia, D.; Barile, A.; Saba, L.; Cella, S. \& Castagna, A. Imaging of shoulder instability. Skeletal Radiol., 49(10):1505-23, 2020.

Giles, J. W.; Owens, B. D. \& Athwal, G. S. Estimating glenoid width for instability-related bone loss: A CT evaluation of an MRI formula. Am. J. Sports Med., 43(7):1726-30, 2015.

Huysmans, P. E.; Haen, P.S.; Kidd, M.; Dhert, W. J. \& Willems, J. W. The shape of the inferior part of the glenoid: a cadaveric study. J. Shoulder Elbow Surg., 15(6):759-63, 2006

Kubicka, A. M.; Stefaniak, J.; Lubiatowski, P.; D?ugosz, J.; Dzianach, M.; Redman, M.; Piontek, J. \& Romanowski, L. Reliability of measurements performed on two dimensional and three dimensional computed tomography in glenoid assessment for instability. Int. Orthop., 40(12):2581-8, 2016

Lansdown, D. A.; Cvetanovich, G. L.; Verma, N. N.; Cole, B. J.; Bach, B. R.; Nicholson, G.; Romeo, A.; Dawe, R. \& Yanke, A. B. Automated 3dimensional magnetic resonance imaging allows for accurate evaluation of glenoid bone loss compared with 3-dimensional computed tomography. Arthroscopy, 35(3):734-40, 2019.

Owens, B. D.; Burns, T. C.; Campbell, S. E.; Svoboda, S. J. \& Cameron, K. L. Simple method of glenoid bone loss calculation using ipsilateral magnetic resonance imaging. Am. J. Sports Med., 41(3):622-4, 2013.

Park, I.; Oh, M. J. \& Shin, S. J. Effects of glenoid and humeral bone defects on recurrent anterior instability of the shoulder. Clin. Orthop. Surg., 12(2):145-50, 2020

Provencher, M. T.; Bhatia, S.; Ghodadra, N. S.; Grumet, R. C.; Bach Jr., B. R.; Dewing, C. B.; LeClere, L. \& Romeo, A. A. Recurrent shoulder instability: current concepts for evaluation and management of glenoid bone loss. J. Bone Joint Surg. Am., 92 Suppl. 2:133-51, 2010.

Saintmard, B.; Lecouvet, F.; Rubini, A. \& Dubuc, J. E. Is the bare spot a valid landmark for glenoid evaluation in arthroscopic Bankart surgery? Acta Orthop. Belg., 75(6):736-42, 2009.

Stefaniak, J.; Lubiatowski, P.; Kubicka, A. M.; Wawrzyniak, A.; Wa?ecka, J. \& Romanowski, L. Clinical and radiological examination of bonymediated shoulder instability. EFORT Open Rev., 5(11):815-27, 2020.

Sugaya, H. Techniques to evaluate glenoid bone loss. Curr. Rev. Musculoskelet. Med., 7(1):1-5, 2014.

Sugaya, H.; Moriishi, J.; Kanisawa, I. \& Tsuchiya, A. Arthroscopic osseous Bankart repair for chronic recurrent traumatic anterior glenohumeral instability. J. Bone Joint Surg. Am., 87(8):1752-60, 2005.

Willemot, L. B.; Elhassan, B. T. \& Verborgt, O. Bony reconstruction of the anterior glenoid rim. J. Am. Acad. Orthop. Surg., 26(10):e207-e218, 2018.

Zhang, H.; Zhu, Y.; Lu, Y.; Li, F. \& Jiang, C. Establishment of a true en face view in the evaluation of glenoid morphology for treatment of traumatic anterior shoulder instability. Arthroscopy, 36(3):668-79, 2020.

\section{Corresponding author:}

Dr. Julio Contreras Fernández

Avda. Pocuro \#2170

Providencia

Santiago

CHILE

E-mail: juliocontrerasmd@gmail.com

Recibido : 23-06-2021

Aceptado: 24-07-2021. 